\title{
Factors Affecting the Primary School Participation of Pastoralists: A Case Study from Ethiopia
}

\author{
Petors Woldegiorgis Woldesenbet, MA, Phd Student
}

Tampere University, Finland

\section{Doi:10.5901/mjss.2014.v5n23p1386}

\begin{abstract}
The study investigated the status of primary school participation of pastoralist children. It was conducted in Bench Maji zone of the S/N/N/P/R/G in Ethiopia. The main focus of the study was to identify the major constraints that hinders the participation of pastoral Suri children. To this end, case study method was employed. Data were gathered from 20 teachers, 16 PTA's, 20 community elders, 5 educational experts, and 2 administrators through in-depth interview and focus group discussion. Community elders, educational experts and administrators were selected by purposive method. Teachers and Parent Teacher Association [PTA] were selected by availability sampling. The data from documentary analysis indicated that the status of pastoral Suri children participation in the primary school is extremely low. Based on findings, school related constraints, socioeconomic constraints and Socio - cultural constraints were found to be the major barriers to the educational participation of pastoral Suri children. Hence, it is concluded that the participation of pastoral Suri children in the primary schools was a function of school related constraints, socio - economic and socio - cultural constraints. Depending on the result of the findings, formulation of policy and strategy to pastoral Suri children was recommended.
\end{abstract}

Keywords: School related constraints, Socio- economic constraints, Socio- cultural constraints

\section{Introduction}

The provision of education to all citizens has become an international issue and national agenda nowadays. Any individual irrespective of age, sex and social status has the right to education as it is stipulated in the provision of the human rights of the United Nations. This right is also enshrined in the constitution of Federal Democratic Republic of Ethiopia (MOE, 2007:1). History gives much evidence that it is now almost more than one century since Ethiopia started taking the first official initiative to provide education for children. As free and non-colonized nations, Ethiopia has started institutionalizing and practicing formal education as means to modernization long before most African countries did. In 1901, Emperor Menelik II (1989-1913) issued a proclamation that every parent would be fined a substantial amount of money if they fail to send their children to school (Teshome, 2003). The initiative had gained momentum in the subsequent regimes. As a senior founding member and active participant of many international and continental organizations that came to exist, there was many time the country made official good promises both to her people and to the outside world to achieve universal primary education within a short time. For example, in 1961, after hosting and subsequently endorsing the resolutions of the famous Educational Conference of newly independent African nations in Africa Hall in Addis Ababa, the country has officially set to achieve universal primary education by the year 1980. This could not be materialized at all even though there was a sort of campaign to expand access by building more and more schools through the support of massive external aid from bilateral and multilateral agencies such as SIDA (Ayalew, 2000). Again through a 10 Year plan a similar goal was set for universal primary education. Yet, after all these long years, Ethiopia cited as first to begin but last to grow, lagging far behind those countries who started pretty late (AAE, 2006). The issue of Universal Primary Education is a desirable and essential goal of the political, social and economic development of the poor nations of the world and has been accepted for a very long time. Soon after achieving independence, many of the former colonies declared their commitment to provide primary education to all their citizens within a reasonable period of time. (Mulugeta, 2007:2). Kenya, Nigeria and Ghana in Africa are examples of nations that expressed strong aspiration for universal primary education (UPE) soon after coming into existence as independent nations. Though significant progress has been made in increasing access to primary education, these countries have still a long way to go to reach the goal of the UPE (Mulugeta, 2007:2). The goal of primary education in most of these countries remains to be elusive even after many years of their commitment. Despite high concern, heavy investments and rapidly rising national enrolment rates at the national level, pastoral nomads are still underserved and disparities with in 
countries are still persist(Hogge,1997). In Ethiopia, pastoralists are estimated to be about 8 million, which constitutes some 13 percent of the total human population. Almost all are found in the marginal border areas and they inhabit the low land peripheral parts of the country. The range land inhabited by pastoralists constitutes about $500,000 \mathrm{~km}^{2}$ or 61 _65 percent of the total area of the nation (Getachew, 2001:1; Carr-Hill, 2005:38). The problem of provision of education and training for pastoralists not only discontinued but also become ever complex \& challenging due to different reasons (MoE, 2002). The people who live in the pastoralist areas of Ethiopia are under the influence of harsh climatic condition, deprived of basic services like educational opportunities. There was no much attention given to these groups of people since the introduction of modern education in Ethiopia. The fact that, in general, pastoral groups are scattered across a wide area, usually in the more inaccessible parts of the country (Carr Hill, 2005:53).

Based on the education and training policy of 1994, all the series of the Education Sector Development Program (ESDP) was launched, with an ultimate goal of increasing access to primary education, equity by expanding schools, improve efficiency by reducing dropout rates and repetition rates. It was also targeted to increase the primary enrolment rate in the underserved pastoralist regions of the country. The educational annual abstract of 2010/11, however indicated that $96.4 \%$ at the national level, whereas the GER for Afar and Somalia pastoralist region is only $40.1 \%$ and $61.3 \%$ respectively (MoE, 2011). Thus, providing education to nomadic communities becomes one of the most challenging and urgent issues currently facing educational policy makers and practitioners in the education system of the African nations (Basiamang, 2006). One of the Nomadic Suri people who found in S/N/N/P/R, at Bench Maji zone is one of the most neglected and disadvantaged area with regard to access to social service like education and health. It is very difficult to achieve the goal of equality of opportunity and universal primary education so long as these groups are forgotten educationally. Therefore, it is imperative and timely to investigate the factors that affect participation and the present status of provision. Moreover, exploring possible alternative strategies and suggesting some solutions is important to increase participation and access to primary education to the deprived children's of pastoralist Surma.

\section{Methods}

\subsection{Study site}

The study was undertaken in Bench Maji zone, S/N/N/P/R/G region, Ethiopia. The S/N/N/P/R/G region is one of the nine regional states where large number of nomadic pastoralists exist. From other administrative zones in the region, Bench Maji zone was selected because the provision of education for nomadic pastoralists found to be below expectation.

\subsection{Participants and sampling}

\subsubsection{Teachers}

Among the total of six schools of the Surma woreda, four schools were included in the study by purposive method. Teachers were selected from four schools. To get a rich data, the total teachers who found within those four schools were included in the study by the assumption that they would have better knowledge about the issue under investigation. The PTA's of those four schools were included by availability sampling in that they are believed to have an ample information since they are the part of administration.

\subsection{Community Elders}

Those who have acceptance and credibility by their respective community were purposely selected from four kebele's with help of local administrators with belief that they are in a better position to describe and explain the socioeconomic and cultural context of their environment.

\subsection{Educational experts and administrators}

Five educational experts, one zonal and one woreda administrators were selected purposely in the assumption that they are expected to deliver pertinent information by virtue of their position. 


\subsection{Data collection instruments}

\subsubsection{Interview}

In-depth interview was used to collect data from all participants in their respective places. Interview with community elders and PTA's were conducted through translation from Amharic to their local language called Suri. The rest of informants were interviewed by Amharic language.

\subsubsection{Focus group discussion}

Focus group discussion was used to triangulate the evidence which secured with interview and personal observation of the researcher. A total of four FGDs were conducted with between six and seven people each. It was conducted after interview so that interview cannot contradict with the issue rose in FGD.

\section{Analysis}

All interviews and FGDs were tape recorded, transcribed, translated into English and used for final analysis. Repeated ideas were identified, coded and thematically analyzed. The themes were derived from objective of the study, interview and FGDs. To keep confidentiality, Participants addressed using abbreviation followed by numbers. e.g Ze1, 2...zonal education expert, T1, T2....Teacher from school 1...etc.

\subsection{Ethical consideration}

In order to ensure the study runs without drawback, Addis Ababa University: in which the researcher is teaching, has wrote a letter of recommendation to S/N/N/P/R/G and the region has wrote a study approval letter to Bench Maji zone so that zone in its turn wrote to the Surma woreda where actual field work is to be conducted. With all participants the researcher reached to consensus and based on that consent all interviews and FGDs were tape recorded.

\subsection{Results}

Even though, sensitization and mobilization of the community plays a significant role in creating awareness about the value of education, this alone cannot bring a fundamental change in making education accessible. It should be supplemented by assessing the need of the community. In the time of the interview, one of the interviewee said the following.

Many other things must be done before we can think about educating our children. First, the government must provide us with necessary facilities, such as vaccines, grazing reserves, and cattle routes. But even if they do all of this, they will not find teachers with the necessary culture. They came here and asked us questions. They wanted to know if we would send our children to school. We told them yes, that if they build a school for our children, at least some of our children will attend even if they have to go for $20 \mathrm{kms}$. But they will have to be sure that our cattle are not affected, because our life depends on them. The people who came there only asked about education and not about our problems. We want to settle, but there is no land for us. We have difficulty in taking our cows from here to dry season pasture, and farmers make us pay just to graze the stubble from their corn stalks. We have difficulty in obtaining necessary vaccinations for our cattle. The people who came here weren't interested in our problems, they only asked us if we want education and we never saw them again. [24-03-10, 11:00 am Tulgit surma]

Child labor is a serious problem especially in developing countries of Africa, Asia and Latin America. In most of the developing countries, children constitute an important labor force both in the family and in production (Kelley, 1987:98). Different research findings from Tanzania, Burkina Faso, Ghana and India show that children are the major sources of labor in the household to fetch water, help to prepare food (girls), looking after younger children and herding cattle's etc. In the work force they (children) help with weeding, holing, with handcrafts production and with trade. They are engaged in these activities from an early age -sometimes as young as six (Rogers, 1980:153).

In FGD, the members of group IV have said the following.

Livestock herding is the main responsibility of children. They participate in the time of seasonal movement. Due to our mobile nature our children move with us. They participate in Gold mining, Fetching water and girls are involved in preparing food, and looking after younger children (06/03/10, 2:30 P.M, Kibish) 
It is clear that parental and family attitude have a strong influence on the decision to invest in children's education. Children's education is a direct result of how much resource and priority parents and families attach to teach their children.

The opinion of group II is indicated in the following manner.

Our fathers and grandfathers were not educated. But they born us and grew us. We appreciate our traditional pastoral way of life of herding the cattle. We don't have exposure or chance to test the fruit of education. It takes long year.(19/03/10, 2:00 P.M, Duku)

Having all these, the study identified the following factors those contributing for the low participation of pastoralists Surma: School related constraints, socio-economic constraint and socio cultural constraints

\subsubsection{School related constraints}

Lack of school facilities may affect enrollments, particularly girls. Yet lack of appropriate teaching and learning materials is likely to affect the performance of both sexes in rural areas. Especially in the areas where there is lack of furniture in schools and where students are required to sit on the floor, parents are probably against sending their children to such school. In some cultures parents are reluctant to send children to school because of the lack of separate toilets and common rooms (World Bank, 1995:116). A study carried out in primary schools of Uganda indicated a positive relationship between students' participation and performance, and better provision of school facilities (Fuller, 1987:226). Moreover, study by (Huyneman and Jamison 1980 in Fuller, 1987:261) have found out positive relationship between students participation, and greater availability of texts and reading materials in Uganda.

The above literature also goes in concordance with response of the teachers which was taken in the time of interview session.

T4: Provision of text books to students activates their learning. Since text books are guides to learning. They are the back bones of instruction and they determine the contents as well as the teaching procedures in the class room. The necessity of text book is indispensable in school since they guide teaching procedures. We reported the shortage of text books so many times for top officials, but not yet responded. It challenged us and our students extremely (09/03/10, Gome school, 8:30 A.M)

There should be strong relation between school and community. Due to different reasons such relation is very weak if not exist in Surma. One teacher of has said the following in the time of interview.

T5: The relationship between school and community play a significant role in the teaching and learning process. The community should participate in the academic life of the students. But they are not willing to come and to discuss about their children academic life and teaching and learning process. The parents visit school only when their children commit serious disciplinary problem or when the students are suspended from the class or when the students fail to do something. The parents would have to help and encourage their child. But the reality is the inverse (24/03/10, 11:00 A.M, Tulgit school)

Children and their families simply do not see the need and convenience of how to adjust their busy lives to demands of the highly structured, rigid time schedules of the formal school system, even when they know that schooling is good and that there is a school in some distance away from home, they simply ignore it. The question therefore, remains how to come up with flexible alternative approaches and programs of basic education that could effectively accommodate the special needs and life conditions of poor families and their children without affecting the quality of education. How to take education to these children who by the very nature of their life styles, cannot come to education (WCEFA, 1990:57-59). following.

In conformity with the above findings, community elders of group III and IV in the time of discussion explained the

CE,III \& IV: The school calendar is inflexible and does not consider our mobility pattern. It is not organized by taking into account when and where we settle. We frequently move with our cattle to Dima (where water and pasture are available). Starting from December up to April, we are on move and then we come back to home in May. The school Calendar of highlanders is not suitable for us. (06/03/10 2:30 P.M Kibish)

Elders of group I and II explained about inflexibility of calendar and its impact in the following manner.

CE,I \& II: Our cows are our lives. Our existence directly depends on them. We drink their blood and milk. We give them as dowry and marry wife. We move with them wherever water and pasture available. Our children go with us. Therefore they drop their learning. (06/03/10 4:00 P.M Kibish) 


\subsubsection{Socio-economic constraints}

It is known that the movement of pastoral people from one place to another for economic purpose is the cause for the discontinuation of children's schooling. Thus, it is possible to conclude that pastoral Suri children were kept away from education because of the mobile nature of their family. In conformity with this the PTA's were approached in the interview session and they stated the following.

PTA3: Children's parents are in constant mobility. This in turn contributes to low enrollment and high drop out. Most of the time, a large number of households, between seven to fifty move together in the time of severe scarcity of water and pasture. Their movement is seasonal mostly from dry season grazing land to wet season pasture land (19/03/10, 2:00 P.M, Kibish)

Reason for dropout lies in the socio economic conditions of the people. e.g. inability to pay school related expenditures, withdrawal of older children to herd cattle, sickness due to malnutrition and lack of medical care and for girls withdrawal from school to act as child nurses to the younger children while mothers are engaged in the family duties are the factors. A major obstacle to children's basic education in Ethiopia is widespread poverty particularly at the household level. The woreda administrator has said the following.

WA: The development constraints that the pastoral Suri confronting are the archaic socio-economic system, poor social services, wide spread animal disease, contraction and depletion of the resource base, lack of extension and development services specially designed for the pastoralists made them to live in absolute poverty and in turn it manifests on participation of education (22/03/10, 10:00 A.M, Tulgit)

Pastoralists live in remote areas often close to insecure international borders and conflict prone regions due to resource constraints. Having to walk long distance in order to go to school for children; especially girls may present serious risk of attack. In northern Kenya for example, schools in remote areas make good targets for the mass abduction of children, particularly girls, by raiding parties and bandit (Carr-Hill and Peart, 2005:48, Kratlli, 2001:33).

One of the administrator have said the following with regard to conflict and of its economic impact.

ZA: Scarcity of resource is the fundamental case for the death of people due to conflict. Those who defeated in the time of conflict explain for their children when and why they are defeated. Then, the children grew with a spirit of revenge. Thus, today one hardly finds the Suri adult without gun. Conflict become habitual act and it creates a kinds of viscous circle (19/03/10, 2:30 P.M, Kibish)

The idea which is forwarded above goes in conformity with the idea of the following news letter

The Suri, who found in Bench Maji zone were engaged in a series of conflict with their neighbors of Sudan Toposa, Bume and Ethiopian Bume due to grazing land for several years. The conflict was serious which took the lives of many peoples and cattle's. The families were dispersed and exposed for hunger and famine. The spirit of revenge goes to the extreme of killing babies and innocent peoples. With this endless conflict the area suffered a lot (Revolutionary Democracy, SPDM; Yekatit 26/2000 Ec)

\subsubsection{Socio cultural constraints}

Pastoralists have their own customs, norms and traditions and the attitude of parents towards education have its own effect on educational provisions and participation. Moreover, pastoralists are considered as change resistant towards modern schooling, which is rooted in their fear of cultural alienation and distortions of traditional values (Carr-Hill and Peart, 2005: 48-49).In conformity with these, the letter written by Surma Woreda councilors to the Minister of Federal affair of Ethiopia clearly indicates the value they attached to education and their attitude towards education.

The community who found in Surma woreda are totally pastoralists and not yet understood the value of education. Though the government is trying its best to change the life of the people, the education sector which is believed to be the corner stone of development is not yet achieved as expected which can be proved from gross enrollment ratio of 31\% both in a formal and non-formal education. It will took long time to achieve EFA which our country ratified... (Ref.No $4 / 7477 / 33 / 2000$ on $17 / 7 / 2000$ Ec)

The attitude of parents toward education is not positive some times because education is perceived as a tool which alienates the young from prevailing social norms and values and parents see no value in education and see no good coming out of it. Teacher of one school has said the following.

T6: Most of the families were not supporting our effort of mobilization. They consider it as we are working for our salary. They strongly believe, as we are going to lose our salary if the students are not in the school. Let alone to encourage their children to learn, they rather encourage being involved in other socio economic activities like cattle herding. Students are complaining this when we asks them why they frequently drops their learning (16/03/10 2:30 P.M 


\section{Anja School)}

Gender inequality is rooted in individual and social bias against girls, not by discriminating but by associating with other factors such as poverty. Here, parents are not willing to invest that scarce resource to girls but they prefer to invest for boys, girls have been ascribed the role of providing domestic labor and child care and the view that girls primary need to be prepared to be wives and mothers, educating girls are considered as wastage of time and money (Car-Hill and Peart, 2005:58-86). In conformity with this the community elders of group 3 and 4 were approached and replied the following.

A man's wealth is determined by the number of cows he has. A daughter's marriage increases the wealth of her family due to the cattle which is given as dowries. The number of cattle that is given as dowry exceeds from $30-50$ cows and at least one gun. To have 5 girls means to have at least 150 or at most 250 cattle and 5 guns. Sending them to school is attached with loosing wealth (06/03/10 3:00 P.M, Tulgit)

Hence, the hindrance of socio cultural factors on educational participation of children is worse on girls. The cultural expectation of girls and the priority given to the future role as mother and wives have a strong negative effect on their educational enrollment and participation.

\section{Discussion}

Distance from home to school was found to be a problem affecting children (students) participation in education in pastoralist areas of Ethiopia. This might be due to uneven distribution of the settlement pattern. In sparsely populated area like Surma, it is difficult to provide social services such as schools at reasonable distances. It is obvious that the lower the population density or the higher the minimum size of school, the greater the distance will be. On the other hand, shortage of students' text book, lack of experienced teachers, poor school community relationship, absence of flexible schedule, in-appropriate medium of instruction and irrelevancy of the curriculum can play a hindering role for the children participation in education. The other factors: lack of water service, shortage of desk, shortage of sport field and lack of separate toilet are also the major school - related barriers affecting children's participation. Besides, the need for children labor, poor economic back ground of family, lack of understanding the benefit of education, absence of upper primary school, mobility of pastoralists, conflict (security issue), Gold mining, poor provision of social service and lack of the development programs designed for pastoralists was also major socio economic constraints that affected the Suri children participation in education. Moreover, lack of interest in education, early marriage, lack of community involvement in encouraging the participation of children in education, fear of the impact of modern education to existing culture, lack of community involvement in educational planning and decision, sudden pregnancy, parents fear towards the content thought, and discouraging the value of girls education and lack of integrated effort by governmental and nongovernmental organizations on matters concerning education were also major problem in hindering children's participation.

\section{Conclusion}

The result of this study revealed, the status of students' participation in primary education was found to be very low. Furthermore, the participation of students in primary education in Surma in most case is concluded to be a function of school related, socio economic and socio cultural factors. Moreover, the participation of children in primary education is the result of the interplay between the demand for education and the supply of services that respond to the nature of that demand and the community needs. Supply includes schools, teachers, text books, desks, different school facilities like chair and field of games; while demand is a direct indication of house hold decisions that are affected by cultural, social and economic factors. Therefore, as the findings of this study show, the major barriers to pastoral Suri students' participation in primary education were found to be school related factors, socio - economic and socio cultural factors. Both in - school factors and out - of - school factors had played a hindering role for participation and it is the manifestation of the absence of coordinated effort between governmental and nongovernmental organization in alleviating the problem of low participation of students. This further has great implication for policy makers and planners in the region. Thus, it is concluded that policy makers and planners in the S/N/N/P/R should pay more attention to increase the demand for and supply of education to improve the pastoral Suri children participation in the primary education with the objective of attaining Education For All by 2015. 


\section{References}

Action Aid Ethiopia (2006). "An Alternative Route to Basic Education for Children in Ethiopia" Addis Ababa

Ayalew Shibeshi (2000). Ethiopia: an Introduction to Culture, Economic, Politics and cooperation. Frankfurt: Brander and Apsel. (Edited by Fellner)

Carr-Hill, R. (2005). The Education of Nomadic Peoples in East Africa Regional Office and UNESC International Capacity Building in Africa. Paris: UNESCO Publishing International Institute for Educational planning.

Carr-Hill, R and Peart, E. (2005). The Education of Nomadic Peoples in East Africa: Djibouti, Eritrea, Ethiopia, Kenya, Tanzania and Uganda, Review of Relevant Literature, Paris: ADB/UNESCO

Fuller, B. (1987). What school Factors Raise Achievement in the Third world? Review of Educational Research Vol:57. No1

Getachew Kassa (2001). Among the Pastoral Agar in Ethiopia Tradition Continuality and Socio- Economic Change. Netherlands: International Book.

Getachew Yoseph (1999). "The Economics of Education and Planning" AAU

Hogge,R.(1997). Pastoralists, Ethnicity and the State in Ethiopia. London: Hoan publishing

Kelly.G.P (1987), "Setting State Policy on Women's Education in Third world: perspectives from Comparative Research" Comparative Education. Vol 23 No.1

Kratli,S (2001). "Education Provision to Nomadic Pastoralists." [Online]. Available: http://www.ids.ac.uk/ids/env/PDFS/NomEdu:pof. Mulugeta Tsegay (2007). Opportunities and Challenges in Achieving Universal Primary Education in Ethiopia. COE: AAU,Vol.I No 11

MoE (2002). Educational Sector Development Program, EMPDA: Addis Ababa

........ (2007)." The strategies designed to Expand primary Education in pastoral Communities of Ethiopia" Addis Ababa: MoE

......... (2011). Educational Statistics of Annual Abstract. Addis Ababa

Rogers, B. (1980). The Domestication of Women: Discrimination in Developing Countries. London: Tavistock Publication.

Teshome N. (2003). Low Participation of Female Students in Primary Education: Acase study of Dropouts from the Amhara and Oromia Region: Ethiopia: A.A: IICBA.

T.G.E (1994). Education and Training policy. Addis Ababa: EMPDA

WCEFA, (1990). Meeting Basic Leavening Needs: A Vision for the 1990. USA: The inter-agency commission

World Bank (1995). Priorities and Strategies for Education. Washington DC: World Bank 